This is an Accepted Manuscript of an article published by Taylor \& Francis in CONTEMPORARY JUSTICE REVIEW on September 2011 (Volume 14, Issue 3, ) available online: http://www.tandfonline.com/ Article DOI:

\title{
A faithful compass: Rethinking the term restorative justice to find clarity
}

\author{
D. Vaandering, Ph.D. \\ Faculty of Education, Memorial University, \\ St. John's, Newfoundland and Labrador
}

A1B 3X8

\begin{abstract}
:
In the field of restorative justice (rj) there is regular debate regarding the terms restorative and justice. In spite of efforts to come to a common vision, this ongoing discussion illustrates how theoretical and practical disagreements have resulted in $\mathrm{rj}$ being characterized as ambiguous and inconsistent within the judicial context and beyond (Gavrielides, 2008; Sullivan \& Tifft, 2005; Johnstone \& Van Ness, 2007). Arising out of research conducted in an education context (Vaandering, 2009), this paper identifies the impact of this ambiguity on educators. More importantly, however, it examines the term justice and discovers that an overemphasis on justice as fairness and individual rights has pulled the field off-course. The paper identifies that what is needed is a broader understanding of justice than that given in the judicial context and makes the case for justice as honouring the inherent worth of all and enacted through relationship. If understood as such, I argue that the terms restorative and justice must remain paired and in place in order to serve as a muchneeded compass needle that guides proponents of rj in the field to their desired destinations.
\end{abstract}

Key words: restorative justice; restorative practice; restorative justice theory; transformative justice; education; narrative inquiry;

A rusty nail placed near a faithful compass, will sway it from the truth, and wreck the argosy.

Sir Walter Scott (1771-1832)

•Email: dvaandering@mun.ca 
In the field of restorative justice (rj) there is regular debate over the terms restorative and justice (Gavrielides, 2008; Sullivan \& Tifft, 2005; Johnstone \& Van Ness, 2007). The term restorative frequently leads to questions about what exactly is being restored. The term justice is seen to be problematic as fields engaging with the principles of rj such as counseling, education, and the environment tend to replace the term with nouns such as restorative practice, restorative approaches, restorative schools, etc. in an effort to avoid any potential connotations the term evokes relating to crime and the judicial system. This ongoing discussion regarding theoretical and practical perspectives has resulted in rj being characterized as ambiguous and inconsistent within the judicial context and beyond (Gavrielides, 2008; Sullivan \& Tifft, 2005; Johnstone \& Van Ness, 2007) in spite of efforts to come to a common vision. These tensions, however, have not impeded the growth of rj initiatives as is evidenced in the proliferation of organizations, books, articles, videos, and websites espousing the value of rj. Yet, as these initiatives grow, differences in perspective are significant and debates and tensions continue. Why?

The fact that practice continues to march ahead of theory in the global social movement of rj (Braithwaite, 2004; Morrison \& Ahmed, 2006: Sherman and Strang, 2007; Wheeldon, 2009) may be part of the reason. To contribute to a stronger theoretical foundation, in this article I argue that an overemphasis on justice as fairness and individual rights has pulled the field off-course and what is needed is a broader understanding of justice. If this more comprehensive perspective is understood amongst advocates of rj, I make the case that when the terms restorative and justice remain paired and in place they act as a compass needle guiding proponents in the field to their desired destinations. 
Gavrielides (2008) identifies that a simple theoretical discussion of definitions will not adequately diffuse the vicious circles created by the conceptual tensions. He states that what is necessary is acknowledging the multidimensional nature of the tensions and exploring each in depth to gradually bring about equilibrium (p. 179). In order to do this effectively however, I assert that an in-depth examination of the terms restorative and justice is far from sterile and single-layered. It is a critical, complex foundational step required for addressing the tensions that exist.

The foundation for this argument arises from a qualitative study that examined the impact of restorative justice on two Ontario public schools (Vaandering, 2009). A key finding identified inconsistency and confusion associated with $\mathrm{rj}$ in the educational context. To fully understand the dilemma in this environment I examined the limited rj literature rooted in schooling, and then turned to the field of law and justice for further clarity. By drawing on both fields, the lack of a common reference point was magnified. Conducting a conceptual analysis from the vantage point of education as opposed to a judicial context where most such discussions are currently positioned, resulted in insights that led to a rethinking of the term restorative justice and discovering it to be a faithful compass needle.

The article is written in four parts. Part I describes the study and how conceptual tensions result in uncertainty and a search for direction. It includes a brief outline of key theoretical discussions and a description of the debates that have caused significant faultlines in the field (Gavrielides, 2008). Part II develops a theoretical argument for maintaining the term justice by exploring what occurs when it is eliminated or when it is accepted. By drawing on the work of critical theorist Paulo Freire (2005), the 
philosophical insights of Buber (1958) and Wolterstorff $(2006,2008)$, as well as the early philosophical perspectives of rj theorists Zehr (2005) and Bianchi (1994), a broader view of justice is presented. Part III illustrates how the term justice serves as a consistent reference point (North) that people can use to orient themselves from any location where they are engaged with the practice of rj to keep them on course. The section extends the theoretical perspectives of Johnstone and Van Ness (2007) as well as Morrison (2007). Finally, Part IV summarizes the argument indicating that reconsidering the term justice can provide a consistent theoretical foundation to guide the growing engagement of many fields with restorative justice. The article concludes by identifying how all involved in rj could travel together in one direction. Permeating each of the sections are three questions: What is justice? What is being restored? How can the term justice be employed across various fields without eliciting connotations of crime?

\section{Looking for direction: Conceptual tensions}

A study examining rj practice situated in the field of education provides a different view than the prevalent judicial perspective from which the contemporary understanding of $\mathrm{rj}$ that focuses on responding to harm has arisen. Though many educators initially engage with $\mathrm{rj}$ as a means for responding to harmful behaviour, their primary role is not to manage behaviour but to educate. As a result in this place, educators engaging with rj are often set up to be pulled in different directions. Much can be learned from their experiences in regards to the foundational principles of $\mathrm{rj}$ for all fields.

The particular study this article draws on employed qualitative, critical- narrative case study methodology in its examination of the impact of rj on two Ontario [Canada] 
public schools. Each school was from a different school board (district) that had recently committed to rj in an effort to address bullying and violence as well as reduce suspension and expulsion numbers. Training had been provided for approximately one-third of the staff in one of the schools; in the other all of the adults had received training. From both schools combined, 37 educators were interviewed and four teachers and two administrators were observed over a six-week period as they went about their daily work. As the researcher, by taking the position of participant-observer and using reflexivity, I was able to critically examine my own perspectives as well as those of the participants (Cohen, Manion \& Morrison, 2000; Harding, 1991; Pillow, 2003). Because of this role, the initial purpose of the study, which was to examine what rj looked like, sounded like, and felt like on the ground, expanded to include a analysis of theoretical frameworks as I began to question my own understanding of rj. Change in the researcher is not uncommon in qualitative studies that employ participant-observation (Denzin, 1978; Patton, 2003; Merriam, 1998). By acknowledging the change additional insights can emerge which was the case in this study and which now form the foundation for this article calling for rethinking the term restorative justice. This coincides with Toews and Zehr's (2003) call for "finding ways of knowing and doing research that reflect the values we espouse in restorative justice" in order to avoid perpetuating harmful hierarchical power structures (p. 257). In that spirit I designed this study and included myself in the research as participant-observer engaging with the participants in a communal dialogic manner in hopes that, like in a rj conference/circle, a fuller story or perspective of $\mathrm{rj}$ might emerge. The theoretical insights arose as I listened to the different voices and thus in the context of this article are presented as my personal experience. 


\section{A. From this location}

In analyzing the formal interviews I conducted it was obvious that educators' perceptions and practices of rj were inconsistent and did not reflect the brief introduction to the philosophical significance of the movement they received in their training. Though many found that the call for a paradigm shift in terms of thinking about the role of rules and the need to repair harm resonated with them, in most cases they interpreted rj as a strategy like others they employed to better manage students. This contradicted my understanding of rj as a philosophy, a way of being, that I had gained from participating in the same trainings the participants had, my own experiences as a teacher, and from extended reading. I became conscious of being "burdened by conceptual tensions" (Gavrielides, 2008, p.178) as the inconsistency I was observing in others reflected my own struggle to find ways to articulate what rj was and why it was important. I became very conscious of what Sawatsky (2009) names the pluck and choose model and the conversion model of engaging with restorative justice in myself and in the participants. In particular the limitations of merely adopting a practice without engaging with wider change (Sawatsky, 2009) became apparent in the school context. To better understand this gap, I examined the literature regarding rj and education and then turned to the theory and philosophy that proponents of rj connected to the judicial field had developed. From these, the various nuances in the principles and approaches taken by practitioners and theorists appeared and shed light on the perceptions and practices of teachers.

What follows is a brief outline of these foundational perspectives as I explored them. This is not intended to be a review of the field as done so adequately by others 
(Johnstone and Van Ness, 2007; Liebmann, 2007; McCold, 2008; Sawatsky, 2009;

Sullivan \& Tifft, 2005) but rather it is intended to reveal why educators find it challenging to decipher the different perspectives and find practical approaches for engaging with rj in a context that is not primarily about behaviour. By highlighting components of the various approaches, the need for a re-examination of the terms justice and restorative emerges.

\section{B. Exploring the field}

Like many educators globally, I was first introduced to rj through the significant work of O'Connell and Wachtel (Wachtel, 1997). Drawing on Maori traditions of justice they initially worked in the context of educating youth involved with crime in New South Wales, Australia and Pennsylvania, USA. This led to O'Connell and Wachtel recognizing the potential of rj for all students in all schools. To explain this concept, a social discipline window was developed as a theoretical framework that focused on the behaviour of students and how educators responded (Wachtel, 1999). A response that used high support and high expectations is considered restorative in that youth are nurtured by the consistent stable engagement of educators WITH students. This relational emphasis was in contrast to school environments where more authoritarian or permissive relationships existed between teachers and students that resulted in doing things TO or FOR students. According to Wachtel and O'Connell, in these contexts students are not consistently taught to take responsibility for their own actions. In early work, Wachtel (1999) coined the terms Real Justice and Safer Saner Schools to describe their work which brought together victims, offenders and their support communities, an approach that sought to move justice from being a retributive, adversarial response to wrongdoing 
to a relational engagement that acknowledged and reinforced the interpersonal connections of community. More recently (2002) the term Real Justice has become a brand name for the approach of their training and graduate school the International Institute for Restorative Practices (IIRP), which explicitly encourages the use of the term restorative practices. Under this umbrella term, restorative justice is considered a judicial restorative practice, restorative schools an educational restorative practice, family group counselling, a restorative practice related to social work, etc. (IIRP, n.d.).

To support their theoretical approach, Wachtel and O'Connell draw significantly on the work of Braithwaite (1989) another early proponent of rj who developed a theory of reintegrative shaming to describe why restorative justice is effective. Using Nathanson's (1996) compass of shame, Braithwaite identified that peoples' response to shame is the theoretical reason for the effectiveness of rj. Differentiating between reintegrative shaming and stigmatized shaming, Braithwaite highlights that when wrongdoing occurs, shame results in both those harmed and those who have caused harm. When this shame is used to stigmatize a person, they are alienated and cut off from community. When the shame is addressed and the community sends a message that they value the participants as people but not the harmful action, then shame is used to reintegrate people into their community. This theory has gained much attention and support through the frequent training sessions the IIRP conducts across the world, but criticisms of the theory exist as the emotion of shame carries with it significant negative connotations (Harris, 2006; Maxwell \& Morris, 2004). In the context of education, this theory may contribute to the confusion educators experience in terms of understanding r $\mathrm{j}$ as distinguishing between reintegrative shaming and stigmatized shaming is difficult for 
two key reasons. First there is a significant power differential between the adults and the students that in the busyness of a school day can easily be misused. In considering the role of shame in rj, this can lead to enacting stigmatized shaming if educators do not clearly understand the difference between the two types of shaming. Second, the language of stigmatized shaming resonates more readily with the language often emphasized in teacher education and professional development programs as well as government and school policies that encourage teachers to better manage their classrooms and student behaviour. Thus, the inconsistent and varied use of key terms teachers encounter in the rj resources available as well as the challenge it is to carry out educational policy with young people, readily contributes to growing ambiguity and understanding of rj. To address this, I found some clarity by turning to the work of those who were instrumental in re-introducing rj principles and practices in Western society prior to it entering educational institutions.

Howard Zehr (2005), an early pioneer in the field promoted rj as a paradigm shift, a different way of understanding justice, one that acknowledged the needs of the victim as the purpose of the judicial system and required that the offender be held accountable for harm done. The paradigm shift moved the focus from the inanimate laws and rules being broken, to the harm caused and suffered not just by those directly involved but also by stakeholders affected indirectly. Zehr's work, grounded in a Judeo-Christian, Mennonite perspective, resonated with my own philosophy and provided a framework for comprehending the practical application Wachtel and O'Connell endorsed.

As a participant-observer in the research, this perspective was deepened with work that draws more significantly on indigenous cultural responses to brokenness in 
community. Pranis, Stuart and Wedge (2003) as well as Rupert Ross (1996) have done much to highlight and recognize that key rj principles originate from ancient and current indigenous traditions that honour the significance of the interconnected nature of community. Within this interwoven cultural milieu, circle processes are employed to find ways for all members of the community to learn from each other's wisdom in addressing conflict and harm done in the community. For me, this indigenous approach served to illuminate how harm done has roots in how the community is structured and interacts. As such it highlighted how rj is a way of being, a philosophy and not simply a response to harm done.

Integrating many of the perspectives put forward to date, more recently Jennifer Llewelyn (2009) has presented a comprehensive relational theory to explain why the judicial system would do well to engage more fully with rj. Her insights point to rj as a "restoration of balanced social relations and reparation of harms and is rooted in values of equality, mutual respect and concern” (nsrj-cura, 2007).

Interspersed throughout these theoretical proposals and discussions on rj is the dilemma put forward by justice advocate Ruth Morris (1998) that questions the use of the term restorative. Stating clearly that restorative allows for a reinforcement of the belief that crime begins with an individual and that it encourages a restoration to unjust social structures, she calls for transformative justice. Transformative justice she states, sees crime and harm as an opportunity for transformative healing for the whole community. She interprets rj as focusing on an incident of harm whereas transformative justice takes a broader view recognizing that harm didn't begin with the act but arose out of a community context and cause. Her insights are echoed in the practice of those who seek 
to reinforce the view that harm done must result in the transformation of social structures, not the restoration of structures and relationships that were the sites for producing the harm in the first place (Lockhardt \& Zammit, 2005; Moore, 2004).

All of these perspectives combined reinforce the potential rj holds for school communities that are looking for improved interaction with students, but also create confusion for how to decipher the field and find a way forward for its effective integration into education. The fault lines Gavrielides (2008) lays out to clarify the debates in the field provide a structure. Though he chooses the judicial system to illustrate his observations as it was from here that the current engagement with rj arose, he indicates that the fault lines are alive and well in other jurisdictions, such as education as my study also discovered. He lays out six existing debates, five of which address rj beyond the judicial context:

- Fault-line \#1: Rj as a new paradigm or rj as a pragmatic, parallel approach. [The old adversarial, retributive paradigm must be abolished and replaced with the values and philosophy of the new paradigm OR rj can broaden the current institutional approach with alternatives and run parallel to it.]

- Fault-line \#2: Rj as a process or rj as an outcome. [A specific process is required to ensure a response is restorative OR $\mathrm{rj}$ is an achieved outcome that brings healing and restoration to the participants. The process for arriving at this healing is not important.]

- Fault-line \#3: Rj as mediation or rj as conferencing. [Participants in the rj conference are only those directly involved in the incident. Other stakeholders are not encouraged to participate for fear of vigilantism OR stakeholders must be present to support and encourage those directly involved but also to assure that their needs are met.]

- Fault-line \#4: Rj as coercive or $r j$ as voluntary. [Participants are strongly encouraged to participate if they wish to avoid punishment OR participants are invited to participate and are discouraged from doing so under duress.]

- Fault-line \#5: Rj principles are flexible or rj principles are not flexible. [Must core principles be adhered to religiously OR can they be flexible?]

These fault-lines could be identified in discussions I had with teachers and administrators who set out to embrace rj but found implementation very challenging. However, because 
of the early implementation stages schools in Ontario are in, the fault lines are not as clearly entrenched between proponents of $\mathrm{rj}$ in education but rather can be found within the training approaches, within specific schools and within individual educators as they grappled with engaging with this new/old approach to peacemaking (Pranis, 2005). I also began to identify the fault-lines within myself. There is the perception that rj in education is a completely new approach - a paradigm shift that requires that all that led to zerotolerance practices be replaced; there is the pragmatic parallel approach that speaks of $\mathrm{rj}$ existing alongside the current codes of conduct schools had in place. There is the disagreement between the emphasis of $\mathrm{rj}$ being on the process and the emphasis being on the outcome. There is confusion about the importance of involving stakeholders beyond those directly involved in the harm done. There are proponents who feel it is alright to coerce people to participate and those who say $\mathrm{rj}$ is only effective when people participate voluntarily. Finally there are those who feel rj principles can be flexible and those that work to establish definite rj principles to govern rj in education.

What is important to note in all of the theoretical work presented here is that $\mathrm{rj}$ is considered first and foremost in the context of behaviour, specifically behaviour that causes harm (Johnstone \& Van Ness, 2007; Sawatsky, 2009; Zehr, 2005). Most proponents of rj recognize a deeper context that highlights community and relationship, but the harmful behaviour is the vehicle that spawns the discussion and exploration of alternative routes to healing. Entering into education as stated earlier, rj has been pulled into a broader context because the primary purpose of schools is not to manage behaviour but to educate people. Grappling with this difference and wishing to shift the focus from behaviour solely, it makes sense that educators such as Wachtel and the IIRP (n.d.), 
Amstutz \& Mullet (2005), and Thorsborne \& Vinegrad (2002) propose dropping the term justice in an effort to focus on relationships. However in doing so, they and others with similar intentions fall into what Bianchi (1994) considers to be a fundamental mistake.

They refrain from a discussion and explanation of the concept of justice. This failure leads to regrettable errors in thinking....Their lack of philosophical reflection on the concept of justice usually makes the results they achieve practically nil or even the very contrary of what they intended. (pp. 1-2)

Bianchi's prediction for ineffective and/or contrary results became evident in the research I conducted and thus challenged me to take seriously the need to explore the concept of justice. It is important however, to acknowledge that my argument is not the first of its kind. Bianchi and Zehr (2005) have made substantial contributions to examining the concept of justice. However, rarely are their contributions given significant attention in $\mathrm{rj}$ literature and rarely does it effectively guide implementation and practice. It is my intention to bring it to the foreground again by reflecting on the concept of justice using Bianchi and Zehr's insights and adding the insights of Freire (2005), Buber, and Wolterstorff $(2006,2008)$. In this way, I aim to illustrate how a clearer, intentional understanding of the terms restorative and justice can help to clarify the ambiguity and inconsistency that exists across the field.

\section{Finding North}

The theoretical argument for maintaining the term justice is presented in two parts. First I illustrate how eliminating the term results in further confusion about what is being restored and encourages practice for the sake of practice. Second, I demonstrate how a careful examination of the concept of justice leads to a broader understanding that 
has the potential for providing clarity that will aid in the development of purposeful, effective, sustainable practice.

\section{A. A compass without a needle: when the term 'justice' is eliminated}

In the field of education it is common for schools engaged with restorative justice to eliminate the term justice in order to emphasize the approach they are taking to address some aspect of how they function as an educational institution. For some the focus is on how students are managed and disciplined, i.e. restorative discipline (Amstutz \& Mullet, 2005) or restorative consequences (IIRP, 2003; Petersen \& Rau, n.d.); for others the focus shifts to the school environment, i.e. restorative school cultures (Cronin-Lampe \& Cronin-Lampe, 2010); for others it broadens further to include the school community, i.e restorative communities (Wachtel, 2005; Morrison, 2007), for some it encompasses all of these, i.e. restorative approaches or practices (Hopkins, 2004; IIRP, n.d.; Doornai, 2009). In most cases, what is inferred or stated explicitly is that this engagement with $\mathrm{rj}$ recognizes, repairs and builds relationships. In spite of the fact that the term justice is eliminated in these contexts, professional and academic literature that is drawn upon as well as school policies and procedures continue to reference the judicial system as being the source of rj. A typical definition of restorative justice included in much of the literature is like the one found in Thorsborne \& Vinegrad (2002) which includes these three principles of rj,

1) Crime (and misconduct) is a fundamental violation of people and interpersonal relationships;

2) Violations create obligations and liabilities;

3) Rj seeks to heal and put right the wrongs. 
From this starting point, proponents of $r j$ in education indicate that $r \mathrm{j}$ is about moving schools from being rule-based to relationship-based school cultures (Amstutz \& Mullet, 2005; Hopkins, 2004; Morrison, 2007; Thorsborne \& Vinegrad, 2002; Wachtel, 1999) so that it touches the experience of all students in a school not just those affected by harmful behaviour. [Characteristics of relational school cultures are presented later in the article.]

The theoretical expansions provided by these pioneers in the field of rj in schools have done much to deepen the entire field in terms of recognizing that harm done comes out of a community context. The growth of the IIRP which I introduced in Part I, is a clear example of this evolution as it promotes using the terms restorative practices to reflect this broader foundation.

Restorative practices is the study of building social capital and achieving social discipline through participatory learning and decision-making...The most critical function of restorative practices is restoring and building relationships. (IIRP, n.d.)

However, what occurs when the term justice is dropped and replaced by various other nouns in hopes of emphasizing relationship and community, is continued and perhaps deepened ambiguity. This is illustrated in discussions with administrators and teachers who after being trained, willingly embrace rj because they find it resonates with their approach to education. Yet, amongst those interviewed in the study (Vaandering, 2009) there was little consistency in terms of identifying and articulating what is being restored. Emphasis was on rj as a strategy for better managing student behaviour; few mention it in terms of it being philosophy because as one participant stated clearly:

For it to be a philosophy you have to use it every single time without any other ... but a tool is something you use, you have a little bag of tricks that you have to pull out and if the need arises for restorative practice it's a really good one to use... I don't consider it a philosophy because that would mean I use it all the time no matter what. (Vaandering, 2009, p. 245)

Why in spite of significant training and eliminating the use of the term justice does this inconsistency and ambiguity continue? I suggest three reasons: 
First, because schools have "traditionally adopted a quasi-judicial approach to the management of student misconduct, modelled on existing western criminal justice systems" (Thorsborne \& Vinegrad, 2002, p. 9) school administrators are attracted to the effectiveness rj has had in the judicial context. Thus, many seeking to address issues of violence, bullying, and harassment after initial attempts using zero-tolerance policies had failed and alienated students, continue to associate rj with student behaviour and management strategies. Like in the judicial context, because past policies and codes of conduct are rooted in an entrenched adversarial approach to addressing behavioural issues, rj tends to be integrated into schools along side the previous adversarial code. When it appears the restorative approach doesn't have the immediate desired outcome, the default position in the midst of a hectic school day becomes the more adversarial procedures with which most people are familiar. Thus dropping the term justice does not eliminate underlying connotations; simply changing the term doesn't ensure that the underlying purpose for implementing $\mathrm{rj}$ is about relationships. A careful analysis of policy statements of schools and districts committed to rj indicate this clearly. Because schools historically have been hierarchical institutions, it is very difficult to change the retributive, adversarial language that has led to the problems in the first place (Vaandering, 2009). This is an echo of what Eisler (2000) states when she describes a domination model of schooling that is based on submission and coercion, a model that was and continues to be prevalent, and a model that we will "unwittingly reinforce" unless we understand how they were created (p. 9-13).

This traditional quasi-judicial, dominator model also puts educators in a difficult position as the lack of clarity and various terms attached to restorative encourages them 
to waffle back and forth between understanding rj as a response to behaviour and a way of being. They feel the social expectation to be in control as a teacher, thereby prompting them to return to the 'judicial' understanding of rj. Yet inherently they know it is a strong relational partnership model (Eisler, 2000) that will provide an atmosphere where they can set clear expectations and provide adequate support for nurturing academic and social well-being of students.

Second, deepened ambiguity results when the word restorative is paired with terms such as 'discipline' or 'school' or 'approach'. Changing the noun increases the confusion in regards to what is being restored as it opens up whole new arrays of possibilities. What is being restored? Is it a person, a relationship, a school, someone's possessions or dignity? Is it the school's sense of control, or ability to produce informed citizens? Without clearly defining what is being restored educators are quick to make assumptions about what it means and most often that tends to be something they want it to mean so that it reflects their personal approach and philosophy. This is the route of least resistance requiring little change on their part and leads to the frequent response that rj is "what we've always been doing anyway." Educators tired of being required to engage with new initiatives, look for permission to avoid what rj has to offer if they sense it will require change on their part (Vaandering, 2009).

Finally, dropping the term justice contributes to ambiguity and the creation of fault-lines in the field because the focus shifts to more practical aspects of the word when attached to a different noun. For example, restorative discipline shifts attention to how-to discipline more effectively; restorative schools shifts attention to how-to be school; restorative approaches focuses on some aspect of how-to be students, educators or 
schools. With the more ambiguous, conflicted term justice out of the way, training is permitted to race or gloss over philosophical and theoretical foundations in order to get to the how-to of education. This is what appeals to educators who are looking for quick, effective solutions to the challenges they face in the classroom. One trainer conscious of this desire for the practical and eager to convey the usefulness of rj, introduces his session stating, "This is a workshop about practice, not philosophy, not theory, but practice." (Vaandering, 2009). As a result, schools engaged with rj run the risk of implementing rj practice simply for the sake of effective practice not for the sake of the building relationships and promoting healing.

Eliminating the term justice does not ensure or contribute to the hoped for development of a relational, partnership school culture, as doing so will not address the structure and policies governing the institution. For change to occur, the power relationships underlying past ineffective practices must be challenged (Eisler, 2000; Morrison, 2005) and harm must be recognized not as an individual behavioural incident but rather as a breach in relationship amongst people and/or the system of which they are a part (Jones, 2004; Lindstrom, 2007; Morrison, 2005). To accomplish this, I argue that engaging with a broader understanding of the concept of justice is necessary.

\section{B. A functioning compass: the term 'justice' as a compass needle}

In my efforts to bring a sense of clarity to the term restorative justice for educators, I found myself returning to the insights of proponents of transformational justice. Ruth Morris' (1998) argument that harm is an opportunity for transformative healing for the whole community pointed to a broader understanding of justice that went 
beyond the particular incident, beyond blame and restitution for a few individuals, to incorporate what I had come to know of rj addressing the collective vulnerability that communities experience in their shared struggles and victories (Moore, 2004). Though I was tempted to advocate for changing the term restorative justice, I recognized that this would be an insurmountable task as it is embedded quite significantly in the field globally. Instead I considered what would occur if the term justice was examined and reclaimed. This led immediately to the question "what is justice?" and it was here in attempting to define the term that I came upon what I currently believe is the pivotal point of the whole dilemma - justice is much broader than the narrow adversarial

\section{focus it is given in the judicial context.}

Significant to note at this point is the fact that the rj movement remains embedded in this judicial context and the narrow adversarial understanding of justice continues to be reinforced and reproduced in the rj movement primarily because the majority of the $\mathrm{rj}$ literature available repeatedly places the origins of our current practice of $r j$ in the judicial field and because key proponents of the movement also speak primarily from their place in this same context. In spite of proponents' best efforts to expand this perspective and advocate for a paradigm shift and culture change (Bianchi,1994; Morris, 1998; Sullivan and Tifft, 2005; Zehr, 2005) as long as it is understood as coming from the judicial context, it will be difficult to broaden. By coming at it from the context of education, I was able to consider justice apart from the justice system simply because I was very unfamiliar with how courts of law functioned. I inadvertently tried to find a way to make sense of it in a manner that matched my own experience and subsequently discovered it was possible to expand the notion of justice. 
Noddings (1999) and Wolterstorff (2008) whose work includes understanding justice in an educational context, directed my attention to a key principle of rj, namely that of repairing harm. Their perspectives on caring and teaching justly led me to consider "what is harm?" which then ultimately led to the deeper question--"What does it mean to be human?" Out of this place of questioning, justice in its primary sense emerged to bring new meaning and clarity for the potential of the term restorative justice.

\section{$i$. What does it mean to be human?}

Though there are many definitions to draw on in terms of defining what it is to be human, Freire (2005) and Buber's (1958) insights on this topic highlight key purposes of rj to date, namely repairing harm and building relationship (Morrison, 2007; Wachtel, 1999; Zehr, 2005).

Paulo Freire (2005) primarily grapples with what it means to be human in his seminal work Pedagogy of the Oppressed in an effort to comprehend how to stop the harm done to peasants in an oppressive regime. Poignantly he points out that people have come to accept that they are 'beings for others' reduced to the level of object by an oppressive, powerful minority. He refutes this perspective that humans are adaptable, manageable beings and calls for transformed social structures that allow people to become 'beings for themselves," with an ontological vocation of becoming more fully human (pp. 73-75). Freire simplifies this by distinguishing between people living 'to be' and living 'to be like' (p. 48). People living to be like are forever seeking approval and direction limiting their potential to discover their uniqueness. They become imprisoned or are convinced that to be imprisoned in the control of another is acceptable and inescapable. People living to be grow to recognize themselves as human and thus begin 
the journey of discovering more fully what it means to be human. They discover that freedom is the point at which they stretch to take on their capacity to be human. With this common vocation recognized and in place, incidents of harm and oppression are reduced as people allow the other to be more fully human as well. Freire commits his life to challenging people to recognize when they have been reduced to the level of an object or have become someone who dehumanizes others, treating them as objects and thereby ultimately turning themselves into an object. For Freire to be human means to be engaged in 'being' a subject that initiates living, not an object that exists to be acted upon or to act on other objects.

This understanding of what it means to be human is echoed in Buber's (1958) influential writing I-Thou where he identifies that "all real living is meeting" (p. 25). Though Buber doesn't focus on the results of objectification, he clearly identifies that being human occurs when people engage in relationships where they honour each other as human. He explains this in terms of the well-known I-Thou

\footnotetext{
The primary word I-Thou can be spoken only with the whole being. Concentration and fusion into the whole being can never take place through my agency, nor can it ever take place without me. I become through my relation to the Thou; and as I become the I, I say Thou. (pp. 24-25)

If I face a human being as my Thou, and say the primary word I-Thou to him, he is not a thing among things, and does not consist of things. ... (p. 16)
}

Buber (1958) crystallizes this relational understanding of what it is to be human when he states, "I think no human being can give more than this. Making life possible for the other, if only for a moment" (p. 261, Buber \& Agassi, 1999). For Buber, this ability to look out for the well-being of another resides at the heart of what it is to be human. Not engaged in this care and respect for one another results in I-It experiences, experiences that ignore and resist the real life that comes from being in relationship. Freire (2005) 
identifies this as well when he states that a fundamental precondition for true humanization is dialogue which he defines as the encounter between people to name the world (p. 137). In other words one is human when they are in relationship with others who encourage them to be. This is a complex balance as relationship on its own can still result in systems of domination and objectification; and striving to be outside of relationship limits ones capacity to become more fully human. Johnstone and VanNess (2007) in outlining the conceptual tensions in the field and presenting options for going forward, touch on this balance when they suggest there is a need for respect amongst proponents of rj. "Respect means not only treating all parties as persons with dignity and worth, but also as people with wisdom and other valuable contributions to offer" (p. 19). Dignity and worth is made evident through an encouragement to make contributions.

Through this lens of what it is to be human, new insight can be gleaned in regards to foundational principles of rj. For example in the comparison that is made between adversarial justice and restorative justice (see Fig. 1) it becomes evident that the comparison is really a discussion based on what it means to be human. This is not regularly elaborated on in the field; what is highlighted however is a focus on harm. Harm considered in the context of what it is to be human takes on deeper meaning.

\section{ii. What is harm?}

The question what is harm may seem simplistic and obvious. Yet because "victim needs and offender responsibility for repairing harm" (Zehr, 2002, p. 21,) has been the central focus of rj since it has come to the fore in the 1970's, it warrants examination especially in the context of what it means to be human. In fact, by drawing attention to the role of harm, I propose that the founders of rj are attempting to make the distinction 
between treating people as humans or objects. Key restorative justice principles are often juxtaposed with key principles of adversarial/criminal justice as the chart indicates.

\begin{tabular}{|l|l|}
\hline \multicolumn{2}{|c|}{ Two Different Views (Zehr, 2002) } \\
\hline \multicolumn{1}{|c|}{ Criminal Justice } & Restorative Justice \\
\hline - Crime is a violation of the law and & - Crime is a violation of people and \\
state. & relationships. \\
- Violations create guilt. & - Violations create obligations. \\
- Justice requires the state to & - Justice involves victims, offenders, \\
determine blame (guilt) and impose & and community members in an \\
pain (punishment) & effort to put things right. \\
\hline
\end{tabular}

Figure 1. Two different views

Looking carefully at this juxtaposition, it becomes clear that rj advocates for maintaining the connection between those who have caused harm and those who have experienced the harm. It originated as a response to criminal justice that is understood as separating the crime from the people involved, a system that determines blame and imposes pain in hopes of deterring recidivism. Set within the discussion of what it is to be human, this perspective and practice of criminal justice turns the offender into an object to be acted on and by omission objectifies the victim by assuming they have no needs resulting from the harm done. By identifying the role of harm and the need to repair harm done, rj identifies that humans suffer harm and laws are objects that are broken. In essence, harm is done to humans not to objects. Freire (2005) makes this clear when he explains that when people are viewed as objects the cycle of dehumanization sets in as it is then possible to justify doing anything to them because objects exist to be acted upon and can be broken, but cannot be harmed.

Seen in this way, harm is injury inflicted on or against a person in any capacity they hold as a human being - physical, emotional, social. It is here that justice moves beyond the boundaries it has been given by the judicial system. 


\section{iii. What is justice?}

Based on the responses to the questions "what is it to be human?" and "what is harm?" injustice occurs when people are turned into objects through relationship. The converse of this then identifies that justice occurs when people are honoured as human through relationship. Wolterstorff (2006) makes this clear when he differentiates between primary justice and justice as judgement:

If meting out justice and rendering judgment become relevant when injustice has occurred or is said to have occurred, then there has to be another kind of justice and injustice than that of meting out justice and rendering judgment. There has to be a justice which has been violated or said to have been violated. There has to be a kind of justice which has broken down or is said to have broken down. Call that kind of justice, 'primary justice'. Only when primary justice has broken down or is said to have broken down do rendering judgement and meting out justice enter the picture. (p. 25)

Wolterstorff continues by arguing that this primary justice is present in social relationships when no one is wronged, when the worth of the other is placed in the forefront of our attention (pp. 31-32). This reflects what Freire promotes in identifying humans as subjects and what Buber identifies as the role of how we see ourselves in relation to other. In later work Wolterstorff (2008) names this distinction even more specifically as justice as inherent rights and justice as right order. The essence of this distinction can perhaps also be understood as social justice which examines the way people live and judicial justice which highlights what ought to be.

In the early days of rj, Dutch criminologist Herman Bianchi (1994) and American criminologist Howard Zehr (2005), both of whom are rooted in a Judeo-Christian worldview, worked hard to identify this distinction as the paradigm shift that was required for rj to be effectively implemented. In looking at their arguments in light of the above questions regarding what it is to be human and what harm is, their ideas may be 
more in line with Wolterstorff's (2006) definition of primary justice or justice-asinherent-rights. Bianchi, drawing on Jewish insight proposed justice as tsedeka where justice was not made manifest in the administration of law but rather in relationship as the following three characteristics indicate. Justice as tsedeka: (a) is substantiated when people's actions show they have had the good of the other in mind; (b) upholds relational truth, where truth is found between people, within dialogue, and judged by its result; (c) occurs when people (both harmed and those causing harm) are set free from the consequences of conflict through reparation of harm. In essence, Bianchi's theory states that justice is not just there, but must be "made effectual" (p. 26).

Zehr (2005), in a similar way highlights the relational aspect of rj where justice is based on the concept of shalom-God's intention for how things are to be among people, between God and people, and even with nature (Yoder, as cited in Zehr, 2005, p. 132). When justice is recognized as concerning itself with need rather than merit, when it is understood as an act of liberation and of love which seeks to make right relationships, its concern is not with measuring if all individuals have equal basic liberties and rights, but rather with how to make things better for the poor and oppressed (pp. 136-157). Specifically Zehr indicates that questions of crime and harm done to others cannot be separated from questions of poverty and power (2005, p.153).

This discussion about justice must also acknowledge contemporary philosopher John Rawls' (2001) seminal work Justice as Fairness. This work has had a significant impact on Western society today as his theory encourages a two-pronged understanding of justice - distributive and retributive. In an effort to access the notion of justice, Rawls idealizes that in a perfect democratic society "justice as fairness" would be the most 
appropriate system for social cooperation. Here, each person would have two basic rights: (a) the same indefeasible claim to a fully adequate scheme of equal basic liberties (i.e., the distributive principle); and (b) social and economic inequality, only when it exists if one is attached to an office open to all or if the inequality is seen to be to the greatest benefit to the least advantaged (i.e., the difference principle). Though these two prongs may well seem to align with Wolterstorff's (2008) perceptions of justice and include a deep respect and honour for people, (Rawls is often seen as being the originator of social justice [Pogge, 2007]), Rawls principles essentially provide the basis for justice as deserts wherein what people are entitled to depends on what they do or do not do (p. 72). Though Rawls' intention may be a society where all are honoured equally, his emphasis on fairness encourages people to examine how they are like others which then according to what Freire and Buber indicate, leads to objectification. Zehr (2005) identifies this as an overemphasis on individual rights that measures if all individuals have equal basic liberties and rights and precludes our responsibility to honour each other as worthy human beings.

Justice as shalom, justice as tsedeka, primary justice, social justice, justice as inherent rights all speak of justice where humans are respected as subjects that are nurtured and set free through respectful relationship. Justice honours the worth of the other, where honour is a praxis that encapsulates both the active relationship and respect for the other. This understanding of justice is what I propose has been usurped by an overemphasis on justice as fairness and individual rights that the judicial system is intent on implementing. It is the difference between doing justice and due justice. Thus what is needed in the field of restorative justice is a concerted effort to remind all people that 
- justice is a call to recognize that all humans are worthy and to be honoured simply because they are human;

- injustice occurs when people are objectified;

- and the term restorative becomes meaningful as it specifically refers to restoring people to a state of being honoured as human.

Understood in this manner, it is crucial that the terms restorative and justice be maintained and paired to provide the much needed reference point that has been lacking. The field has been functioning in many instances like a compass without a needle. Justice understood in its primary sense serves as the consistent reference point (North), always reminding us what it is to be human. The term restorative justice serves as the compass needle that allows us all to keep our bearings as rj moves into different fields and directions.

\section{Aligning the compass with a destination}

How does having this reference point clarify the theory and practice of rj? I begin with theory.

Johnstone and Van Ness (2007) in their chapter The meaning of restorative justice have distilled the tensions in the field to an identification and description of three general conceptions of restorative justice - the encounter conception, the reparative conception, and the transformative conception. The encounter conception involves stakeholders meeting to decide what needs to be done as a result of the action. The reparative conception seeks to heal and repair harm that is done rather than impose equal harm on an offender. The transformative conception looks for transformation of social structures and interactions that have allowed for harm to occur. To further describe the reasons for the tensions they use a metaphor of a three-storey house that has been built on a hillside that allows for entry into any one of the three floors from the outside. The first storey of 
the house is the transformative conception that allows for the broadest application of the three; the second and third stories represent either the reparative or the encounter approach. They are smaller and offset from each other with porches etc. as they share similar principles but not all. The metaphor provides a clear image of what is occurring in the field. Through it Johnstone and Van Ness make the case that there is much overlap amongst each conception as they encounter, repair and transform. The differences, they say, lie in where each places the emphasis and are a result of the deeply contested nature of the concept of restorative justice. Rather than work to resolve those differences, they suggest the field would do well to accept the differences for the wisdom and valuable contributions each can make (p. 16-20).

Though there is merit in this, my argument for a broader understanding of justice, I believe can go a long way towards resolving the tensions that exist. We need not simply 'accept' difference. What is missing in Johnstone and Van Ness' (2007) analogy is the foundation of the three-storey house. If a common, broader understanding of justice is embraced by all proponents in the field, it will serve as the foundation out of which all the different conceptions operate. A reparative conception of rj will be strengthened if people have as their goal not just to repair harm done but also to restore people to being humans and not objects. An encounter conception will be strengthened if the encounters are set up with the goal of guiding participants to honouring each other as human. A transformative encounter is strengthened as clarity and guidance is provided for the systemic changes. The reason for the transformation is clear as it would be able to provide the freedom for becoming more fully human. Without the foundation being firmly in place, the house is at risk of toppling especially since new stories are being 
added and positioned haphazardly above the first. The proverbial house on the sand needs to become the house on the rock.

A similar theoretical case can be made in education circles where Blood and Morrison (2007) have made sense of the discrepancies in education circles by creating a triangle to represent an integrated whole school model of restorative justice. This model currently has as its foundation preventative, proactive approaches with the goal of reaffirming relationships. These approaches are used to engage the whole school population in relational practices such as social skills programs, curricula, and school policies. Built on this foundation are approaches such as corridor conferencing, peer mediation, and problem solving circles for the purpose of managing difficulties and disruption arising with some students with the goal of repairing relationships. The peak of the triangle represents full restorative justice conference approaches taken with 1-5\% of the population that require intensive attention for the rebuilding of relationships.

Looking through the lens of justice as honouring the worth of the other, this whole school model of restorative justice also has no foundation to draw upon. Though there is consistency evident throughout each of the levels in regards to an emphasis on relationship, there is nothing in place that will prevent the approaches from encouraging participants to remain or slip further into objectification of each other. This is evident in the fact that each of the three levels of the triangle exists primarily to target inappropriate, disruptive behaviour. It could be argued that the primary level is proactive and thus focused not on behaviour but relationship. However, in describing this primary level, Morrison (2007) indicates, "the aim is to develop and affirm students' social and emotional competencies and skills, particularly in the area of conflict resolution, so that 
students are able to resolve differences in respectful and caring ways" (p. 107, emphasis added). Looking back at the discussion of what it means to be human, this theoretical approach teeters as a result of placing significant emphasis on relationship while forgetting about the reason for striving for positive relationship. .

What my argument contributes to Blood and Morrison's (2007) model is a foundation out of which each of the three they suggest can grow. The goal of this level however is different than that of changing or managing student behaviour. Its emphasis would be identified as our common human vocation of 'becoming more fully human' (Freire, 2005) through relationship. This foundation provides a definite purpose for the encounters we have with each other in schools and reinforces the calling of schools to be institutions of learning rather than institutions that exist to control behaviour.

Looking back now to the fault-lines that Gavrielides (2008) suggests, defining justice as honouring the worth of the other through relationship provides a means for assessing the purpose of each of the differences. Here the practical contribution of having a common reference point becomes evident. For example, in regards to faultline \#1 the question can be asked, does rj as a new paradigm honour the worth of the other and support a common vocation of becoming more fully human through relationship? If yes, than it can be accepted as a rj principle. Does rj as a pragmatic parallel approach honour the worth of the other? Again if yes, then it continues as it is. But if it becomes evident in a school either approach does not honour students, then students are at risk of being turned into objects, and continuing in this manner will undermine the potential of rj as cooptation will occur. This is a very serious concern as r $j$ will then be used to harm and manipulate the people involved under the guise of being committed to repairing harm. 
Each of Gavrielides fault-lines could be assessed in a similar manner to gauge and inform the various principles that are being adhered to in the field. Fault-line \#2: Does the rj process employed provide people with a greater sense of their humanity? Does the outcome of the rj practice acknowledge that all involved are human? Fault-line \#3: Does the mediation allow for participants to participate in such a way that the humanity of all stakeholders is enhanced? Does the rj conference that includes all stakeholders provide a process that guides participation that honours each participant? Fault-line \#4: Is it possible to coerce people to participate and still treat them as worthy? Does invitational participation prevent objectifying people? Fault-line \#5: Do each of the rj principles adhered to honour or measure participants? By excluding or adding some principles, does the rj practice begin to measure people?

To further illustrate the practical contribution that understanding justice as honouring the worth of all through relationship provides, I present an initial simple application I have experienced personally and observed in educational institutions that could be applied in every context where rj is engaged. By asking myself the following three simple reflective questions, like a compass needle, I am consistently pulled back to the foundational elements of restorative justice described in Part II. Am I measuring? Am I honouring? What message am I sending? Asking am I measuring? is another way of asking if I am judging and objectifying someone for selfish, domineering purposes. Asking am I honouring? is a way of checking to see if I am doing all I can to let someone become more fully human, to let someone be who they are, to encourage them in contributing what they can. Asking what message am I sending? provides a way of double checking from the other's perspective what I am doing. Are they thinking they are 
being measured and judged or are they thinking I honour them as a human being?

(Vaandering, 2009).

Committed to rj as a way of being, these three questions guide how I interact with others personally and professionally. Committed to the implementation of $\mathrm{rj}$ in educational institutions, these three questions can serve to guide and assess whether teaching practice, administrative practice, policies and programs, as well as student and community interaction are rooted in an understanding of justice that honours every person. Committed to $r j$ in any profession, these questions become a guide that acknowledges there is a specific foundation out of which rj practice grows.

To illustrate this, I share examples in my personal experience as well as an example of an institutional experience. In my own life the questioning took the form of an internal dialogue that occurred before, during and after my interactions with people: Am I honouring this person, doing what I can to give them the freedom to be who they are? Or am I measuring this person, judging them to see if and how they fit into what I might consider acceptable, measuring them to see if I can manipulate them for my benefit? What message did I send that person or that group of people? Did they leave feeling measured and judged or honoured and respected? That person who is angry with me, did I convey to her that I did not think she measured up to my expectations? That person who told me he appreciated how I listened to him, how did I convey to him that he was worthy? And so on. What I discovered through these conversations with myself when I was brutally honest was that I was much more inclined to measure people and judge people in spite of my commitment to do otherwise. In grappling with this, the reality of living in a society that is bent on measurement, evaluation, economic pursuit, 
and competition emerged and a commitment to honouring people for their humanity was counter-cultural. At every turn, I found myself staring in the face of a way of being that objectified who I was and who my fellow human beings were. Committing to rj was and continues to be exhausting (Vaandering, 2009).

Applying these questions in an institutional context had similar results. Educators introduced to justice as honouring the worth of all, implemented rj into their practice and discovered the far reaching effects of looking at people through this different lens. What began as a strategy that they anticipated would respect students who had been harmed and caused harm, turned into a reflective practice that challenged educators to examine how the institutional structure itself, all its policies and practices, the curriculum and pedagogy, sent messages that honoured or measured school participants. Educators, myself included, became painfully aware that how we spoke to our students was often from a place of dominance where we were commanding students rather than dialoguing with them; it became evident that the math problemsolving questions encouraged selfish measuring and judging with their attempts at motivating students to buy and sell, enlarge their property and count their possessions; assessment and evaluation strategies became glaring examples of objectifying students where after spending weeks encouraging and supporting them in their efforts to learn, a test or report card mark proclaimed loudly that they did or did not measure up. Again wherever we turned we realized that choosing to honour people was countercultural and that the educational institution was in most cases not designed to honour the people it served. Implementing rj required commitment and that commitment as teachers and administrators express is exhausting (Vaandering, 2009). 
In spite of the effort required to honour people as worthy, along with exhaustion, comes a perspective on living that resonates with who we are as human beings. It is this perspective that Zehr (2005) speaks of as a paradigm shift, and that Freire (2005) identifies as a cultural revolution. That revolution takes place in and through the lives of individuals and communities who live the reality that rj is a way of being, a life style, a worldview, a philosophy. If we can honour people regardless of what they do or say, regardless of whether they have committed a crime, broken a school rule, or hurt another human being, we consider what we can do that would allow them to be more fully human, to be free. If we honour people it opens the door to recognizing them as part of a broader community that has an impact on others. We recognize more fully what we would feel like if we were in their shoes. Honouring people sends us seeking ways to maintain and build connections; measuring people allows us to think of people as disposable objects and we have no problem cutting our connections with them.

Though there have been many attempts at defining rj that have accumulated to a point where there seems to be a tradition that says rj resists a complete definition (Wheeldon, 2009), in light of the details in this paper, I believe the following contribution may be significant. I submit it in hopes that perhaps it will contribute a sense of stability and consistency in the field while at the same time be flexible enough to allow the various jurisdictions freedom to develop effective processes and outcomes.

Rj acknowledges justice as honouring the inherent worth of all and is enacted through relationship. As such it affects all social structures. When something occurs that undermines the well-being of some, rj provides a space for dialogue so that the humanity of all involved and affected can be restored and each person can once again become a fully contributing member of the community of which they are a part. 
As different proponents and fields engaging with rj grow and encounter roadblocks, keeping in mind the essence of what it means to be human and challenging ourselves to reflect critically on our own actions, there is greater potential for rj guiding significant social structural change in a wide variety of contexts.

\section{Conclusion: Travelling together in one direction}

Coming to the end of this article, which describes the experience of an education researcher working to make sense of how to incorporate rj into schools, as the reader you have opportunity to reflect on the argument presented in the context of your own involvement with rj. The article sets out clearly that if justice is understood as honouring the worth of the other through relationship, the term restorative justice is significant, and meaningfully describes its process, outcome and foundational philosophy. If understood as such it narrows the gap created by rj practice continuing to march ahead of theory and suggests a concrete solution that contributes to clearing up the ambiguity and inconsistency that currently plagues the field and holds it back from being more widely and deeply effective.

As a final illustration of this and as a challenge for all proponents of $\mathrm{rj}$ I reiterate the insights of Dyck (2006) who states in Reaching toward a structurally responsive training and practice of restorative justice:

It is puzzling to see how many proponents of restorative justice can limit their focus to only the correctional aspects of restorative justice ... and refuse to take into account the "transformative," economic, and structural dimensions of justice, that is, the social structural conditions that constrain the lives of us all and affect the extent to which any one of us can live restorative lives. (p. 537) 
Because my own personal and professional engagement with rj resulted in seeing rj as encompassing all social structural conditions, the awareness of this limited perspective of rj that Dyck finds puzzling, I surmise, has come about because of his own lived experience with rj. Unless one has experienced in some way the ah-ha moment that occurs in a restorative justice dialogue it is difficult to recognize how rj is about social, structural conditions. In an attempt to identify how this awareness arises consider what happens in a rj circle experience. A rj circle has been organized to repair harm where people who have been harmed, people who have caused harm, and their supporters are provided a space in which the stories of each can be heard. The crucial moment occurs when a facilitator wisely encourages each person, including the one who has caused harm, to express their needs in order for healing to occur. Though difficult to articulate, what occurs in this moment in time is the opportunity for a sense of collective vulnerability to arise (Moore, 2004), a sense of 'there but for the grace of God go I'. And it is in this space that the group gathered can look beyond the incident to the context of the incident which will include each of them personally as well as the social structural conditions in which they find themselves in. As suggestions for repairing harm come forward through the awareness of the needs expressed, they can then include recommendations for change in the structures in which participants find themselves.

To recognize that rj encompasses social, structural conditions requires that proponents engage with rj not solely from the outside as a solution for others who have been affected by harm but from the inside as a way of being for themselves. This distinction was evident with educators, many of whom when interviewed indicated they would encourage students to participate in circles, but would not participate themselves 
stating they weren't the kind of person to share their feelings (Vaandering, 2009). Freire (2005) uncovers what is going on here in his discussion of oppressors and oppressed. He explains that unless one becomes conscious of being objectified, unless one becomes conscious of their capacity to objectify others, in other words unless one becomes conscious of dehumanization, humanization cannot be nurtured.

From this premise, I have argued that defining justice in its primary sense as honouring the worth of the other and challenging ourselves with questions such as am I honouring, am I measuring, what message am I sending, people become personally and collectively conscious of their capacity to allow themselves to be objectified and to objectify others. One cannot arrive at this point instantly. It is a complex journey and one that requires a faithful compass with a needle that keeps us headed in a definite direction.

\section{Notes on Contributor:}

Bio:

Dorothy Vaandering is assistant professor, Faculty of Education, Memorial University, Newfoundland and Labrador. Her on-going research and writing examines how restorative justice in education affects and informs pedagogy, praxis and discipline.

Dorothy Vaandering--Ph.D.

Assistant Professor--Social Studies

Faculty of Education

Memorial University of Newfoundland

St. John's, Newfoundland and Labrador A1C 5S7

dvaandering@mun.ca

Phone: 709-864-3266

Fax: 709-864-2345 


\section{References:}

Amstutz, L., \& Mullet, J. (2005). The little book of restorative discipline for schools. Pennsylvania: Good Books.

Bianchi, H. (1994). Justice as sanctuary. Bloomington, Indiana: Indiana University Press.

Braithwaite, J. (1989). Crime, Shame and Reintegration. Cambridge University Press.

Braithwaite, J. (2004). Emancipation and hope. The ANNALS of the American Academy of Political and Social Science, 79-98.

Buber, M. (1958). I and thou (R. Gregory Smith Trans.). Edinburg: T\&T Clark.

Buber, M., \& Agassi, J. B. (1999). Martin Buber on psychology and psychotherapy: essays, letters, and dialogue. Syracuse Univ Pr.

Chase, S. (1995). Taking narrative seriously. In R. Josselson, \& A. Lieblick (Eds.), Interpreting experience: The narrative study of lives (pp. 1-26). Thousand Oaks: Sage Publication.

Clandinin, D. J., Huber, J., Marilyn, H., Murphy, M. S., Orr, A. M., Pearce, M. et al. (2006). Composing diverse identities. New York: Routledge.

Cohen, L., Manion, L., \& Morrison, K. (2000). Research methods in education (5th ed.). London: Routledge \& Falmer.

Cronin-Lampe, K., \& Cronin-Lampe, R. (2010). Developing a restorative school culture: The blending of a personal and professional 'pilgrimage'. Explorations: An EJournal of Narrative Practice Retrieved November 11, 2010, www.dulwichcentre.com.au/explorations-2010-1-kath-and-ron-croninlampe.pdf.

Doornai, A. (2009). Restorative practices for safe and supportive schools. Canadian Teacher, 5(4), 7.

Dyck, D. (2006). Reaching toward a structurally responsive training and practice of restorative justice. In D. Sullivan, \& L. Tifft (Eds.), Handbook of restorative justice: a global perspective (pp. 527-545). London: Routledge.

Eisler, R. T. (2000). Tomorrow's children: a blueprint for partnership education in the 21 st century. Boulder, Colo.: Westview Press.

Freire, P. (2005). Pedagogy of the Oppressed (30th ed.). New York: Continuum. 
Gavrielides, T. (2008). Restorative justice--the perplexing concept: Conceptual fault-lines and power battles within the restorative justice movement. Criminology \& Criminal Justice, 8(2), 165-183.

Harding, S. (1991). Strong objectivity and socially situated knowledge. In Whose science? Whose knowledge? (pp. 138-163). New York: Cornell University Press.

Harris, M. K. (2006). Transformative justice: the transformation of restorative justice. In D. Sullivan, \& L. Tifft (Eds.), Handbook of restorative justice: a global perspective (pp. 555-566). London: Routledge.

Harris, N. (2006). Reintegrative shaming, shame, and criminal justice. Journal of Social Issues, 62(2), 327-346.

Hopkins, B. (2004). Just schools: a whole school approach to restorative justice. London: Jessica Kingsley Publishers.

IIRP (2003). Roundtable discussions 2 (video), Bethlehem, PA: International Institute for Restorative Practices.

IIRP. (n.d.). What is restorative practices? Retrieved January 2008, http://www.iirp.org/whatisrp.php.

Johnstone, G., \& Van Ness, D. W. (2007). Handbook of restorative justice. Portland: Willan Publishing.

Jones, T. S. (2004). Conflict resolution education: The field, the findings, and the future. Conflict Resolution Quarterly, 22(1-2), 233-267.

Liebmann, M. (2007). Restorative justice: How it works. London ; Philadelphia: Jessica Kingsley Publishers.

Lindstrom, S. R. (2007). Review of school violence intervention best practices. Context: The Journal Recognizing Student Health Professionals Engaged In Their Communities, 1(Fall).

Llewellyn, J. (2009). Relating to justice. Paper presented at the National Restorative Justice Symposium, St. John's, NL.

Lockhart, A., \& Zammit, L. (2005). Restorative justice: Transforming society. Toronto: Inclusion Press.

Maxwell, G., \& Morris, A. (2004). What is the place of shame in restorative justice? In Critical Issues in Restorative Justice (pp. 133-142). Monsey, NY: Criminal Justice Press. 
McCluskey, G., Lloyd, G., Kane, J., Riddell, S., Stead, J., \& Weedon, E. (2008). Can restorative practices in schools make a difference? Educational Review, 60(4), 405-417.

McCold, P. (2008). The recent history of restorative justice: Mediation, circles, and conferencing. In D. Sullivan, \& L. Tifft (Eds.), Handbook of Restorative Justice (pp. 23-51). London: Routledge.

Moore, D. B. (2004). Managing social conflict--the evolution of a practical theory. Journal of Sociology \& Social Welfare, 31(1), 71(21).

Morris, R. (1998). Why transformative justice? Paper presented at the ICCPPC World Congress, Mexico City.

Morrison, B. (2005). Building safe and healthy school communities: restorative justice and responsive regulation. International Institute for Restorative Practices 6th International Conference.

Morrison, B. (2007). Restoring safe school communities. Sydney: Federation Press.

Morrison, B., \& Ahmed, E. (2006). Restorative justice and civil society: emerging practice, theory, and evidence. Journal of Social Issues, 62(2), 209-215.

Nathanson, D. (1996). Knowing feeling: affect, script, and psychotherapy. New York: W.W. Norton \& Company, Inc.

Noddings, N. (1999). Care, justice, and equity. In M. S. Katz, N. Noddings, \& K. A. Strike (Eds.), Justice and caring: The search for common ground in education (pp. 7-20). New York: Teachers College Press.

NSRJ-CURA. (2007). Introduction. Retrieved January 2010, www.nsrj-cura.ca.

Peterson, D., \& Rau, C. (n.d.). Restorative justice in the classroom: Lesson 2 class meetings. Retrieved November 2010, www.sacs.ca.

Pillow, W. (2003). Confession, catharsis, or cure? Rethinking the uses of reflexivity as methodological power in qualitative research. Qualitative Studies in Education, 16(2), 175-196.

Pogge, T. (2007). John Rawls: His Life and Theory of Justice. Oxford University Press.

Pranis, K. (2005). The little book of circle process: a new/old approach to peacemaking. Pennsylvania: Good Books.

Pranis, K., Stuart, B., Wedge, M. (2003). Peacemaking circles: from crime to community. Minnesota: Living Justice Press. 
Rawls, J. (2001). Justice as fairness: a restatement. Cambridge, Massachusetts: The Belknap Press of Harvard University Press.

Ross, R. (1996). Returning to the teachings: Exploring Aboriginal justice. Toronto: Penguin.

Sawatsky, J. (2009). The ethic of traditional communities and the spirit of healing justice : studies from Hollow Water, the Iona Community, and Plum Village. London ; Philadelphia: Jessica Kingsley Publishers.

Sherman, L., \& Strang, H. (2007). Restorative justice: The evidence. London: The Smith Institute.

Shulman, L. S. (1996). Just in case: Reflections on learning from experience. In J. Colbert, P. Desberg, \& K. Trimble (Eds.), The case for education: Contemporary approaches for using case methods (pp. 197-217). Boston: Allyn and Bacon.

Sullivan, D., \& Tifft, L. (2005). Restorative justice: Healing the foundations of our everyday lives. Monsey, NY: Willow Tree.

Thorsborne, M., \& Vinegrad, D. (2002). Restorative practices in schools: Rethinking behaviour management. Queensland: Inyahead Press.

Vaandering, D. (2008). Dissertation field notes.

Vaandering, D. (2009). Towards effective implementation and sustainability of restorative justice in Ontario public schools: A critical case study. Unpublished dissertation, University of Western Ontario, London.

Wachtel, T. (1997). Real Justice. Pennsylvania: Piper's Press.

Wachtel, T. (1999). SaferSanerSchools: Restoring community in a disconnected world. Retrieved February 2000, http://www.iirp.org/library/safersanerschools.html.

Wheeldon, J. (2009). Finding common ground: restorative justice and its theoretical construction (s). Contemporary Justice Review, 12(1), 91-100.

Wolterstorff, N. (2006). Teaching justly for justice. The Journal of Education \& Christian Belief, 10:2, 23-37.

Wolterstorff, N. (2008). Justice: Rights and wrongs. Princeton: Princeton University Press.

Yoder, P. B. (1987). Shalom: The Bible's word for salvation, jusice, and peace. Newton, Kansas: Faith and Life Press. 
Zehr, H. (2002). The little book of restorative justice. Intercourse, PA: Good Books.

Zehr, H. (2005). Changing lenses: A new focus for crime and justice (3rd ed.). Waterloo: Herald Press.

Zehr, H., \& Mika, H. (1998). Fundamental concepts of restorative justice. Contemporary Justice Review, 1(1), 47-55. 